\title{
Evaluation of the Results of Management of Humeral Shaft Fractures Using Flexible Intramedullary Nails
}

\author{
Gad Ragheb Abdel Baki, Abd El Alim Mohamed Mohamed, Kareem Mohamed Naguib Yousef Elsharkawy \\ Department of Orthopedic Surgery, Faculty of Medicine, Al-Azhar University \\ Corresponding author: Kareem Mohamed Naguib Yousef Elsharkawy, Tel: (+20)01002387158, E-mail: \\ kareemelsharkawy22@yahoo.com
}

\begin{abstract}
Background: the humerus is the most mobile long bone of the upper limb. Humeral shaft fractures comprise about 3 to $5 \%$ of all body fractures.

Objective: the aim of the work was to assess the results of using the flexible intramedullary nails in the treatment of humeral shaft fractures.

Patients and Methods: the study included 20 patients presented to Alexandria Police Hospital and El-Zahra Hospital, suffering from humeral shaft fracture. A full workup including history taking, clinical examination and radiological evaluation as well as laboratory investigations was performed for every patient on admission.

Results: the results obtained after a mean follow up time of 32 weeks, were excellent in twelve patients (60\%), good in six patients (30\%), fair in one patient (5\%), and poor in another one patient $(5 \%)$. The difference between excellent and good groups was statistically significant, that the younger the patient the more rapid the fracture healing occurred. Conclusion: flexible intramedullary nailing is a simple, easy semi rigid and quick technique for stabilization of humeral diaphyseal fractures in selected cases of humeral shaft fractures in different ages.
\end{abstract}

Keywords: Management of Humeral Shaft Fractures, Flexible Intramedullary Nails

\section{INTRODUCTION}

Trauma has been the leading cause of mortality and morbidity since the beginning of mankind and is on the rise in the present age. Fractures of the shaft of humerus are commonly encountered by orthopedic surgeons, representing 3 to $5 \%$ of all fractures ${ }^{(1)}$.

There is a bimodal distribution of humeral shaft fractures, with a peak in young male patients due to high energy trauma (road traffic accidents, falling from a height, blow to the arm and gunshot wounds), and another large peak in older females usually by simple falls ${ }^{(1,2)}$.

Diaphyseal fractures of the humerus could be managed by both conservative methods as well as surgically also. The goals of treatment are to achieve union with acceptable humeral alignment. So, patients can resume their prior level of function ${ }^{(2,3)}$.

Conservative treatment has its demerits such as prolonged limb immobilization, the need for constant cooperation, compliance and follow ups. The conservative methods of treatment include U-shaped slab, hanging plaster cast, prefabricated functional braces, and simple sling ${ }^{(3,4)}$.

Surgical fixation of humeral shaft fractures could be: surface fixation using plate and screws, intramedullary fixation either antegrade or retrograde using interlocking nails, rush pins, flexible intramedullary nails, Marchetti-Vicenzi retrograde nails, and Halder humeral nail, as well as external fixation either by uniplanar, biplanar or Illizarov fixators $^{(2,4)}$.

Plate osteosynthesis has always been a gold standard and always given a good result for union of the bone if properly done according to principle of Open Reduction Internal Fixation but the complete compression is achieved as the primary union should be achieved with absolute fixation, but has the disadvantage of excessive periosteal stripping, large incision and increased chances of infection and iatrogenic radial nerve palsy, less secured fixation in an osteopenic bone, there may be stress raiser in primary healing in absolute fixation compared to the callus healing seen in relative fixation with an intramedullary nailing ${ }^{(5,6)}$.

The elastic nail method was developed by Küntscher and the principle was 3 point fixation when introduced in the medullary canal of long bones and was first used in the fracture of long bones of lower extremities and soon became very popular method for fracture fixation of long bone and later used for diaphyseal fracture of humerus ${ }^{(7)}$.

\section{AIM OF THE WORK}

The aim of the work was to assess the results of using the flexible intramedullary nails in the treatment of humeral shaft fractures.

\section{PATIENTS AND METHODS}

The study included 20 patients presented to Alexandria Police Hospital and El-Zahra Hospital, suffering from humeral shaft fracture.

A full workup including history taking, clinical examination and radiological evaluation as well as laboratory investigations was performed for every patient on admission.

\section{Written informed consent:}

An approval of the study was obtained from Al-Azhar University Academic and Ethical Committee. Every patient signed an informed written consent for acceptance of the operation. 


\section{1) Methods of examination:}

Data was collected according to the following sheet:

a) History.

b) Clinical examination.

c) Radiological evaluation.

\section{2) Methods of treatment:}

First aid treatment:

- The fractured limb was splinted by U-

shaped slab.

- Analgesic and anti-oedematous

measures were prescribed.

- Patients were kept under observation in the hospital till time of surgery with management of any associated injuries and other medical conditions.

\section{Surgical technique:}

$>$ All patients were treated by elastic intramedullary nailing inserted under image intensifier control, using two pre-bent titanium nails inserted in retrograde fashion.

Basic requirements of this technique included:

- Titanium nails (400 $\mathrm{mm}$ in length, of different diameters; $2.0 \mathrm{~mm}, 2.5 \mathrm{~mm}, 3.0$ $\mathrm{mm}, 3.5 \mathrm{~mm}, 4.0 \mathrm{~mm}, 4.5 \mathrm{~mm}$ )

- Bone Awl

- Cannulated T-Handle inserter

- Nail cutter

- Mallet

- Steps of surgery:

- The operation was carried out under general anaesthesia and complete aseptic conditions. The patient was positioned in a supine position.

- An image intensifier was positioned so that it can be rotated to obtain antero-posterior and lateral views of the whole humerus from the shoulder to the elbow joint.

- The entire arm including the shoulder and elbow was prepared as an operative field. Gentle external manipulation was performed until adequate reduction was obtained and confirmed by fluoroscopy.

- The diameter of the individual nail was chosen by a calculation (nail diameter $=$ minimum canal diameter $x$ 0.4). To avoid varus or valgus angulation, both nails were of identical diameter.

- Each nail was pre-bent at the same point by hand to an angle of $30^{\circ}$, ensuring that the tip lies in the same plane as the plane formed by bending, and that the apex of curvature lies at the level of the fracture site. In order to achieve optimum reduction, stabilisation and alignment of the fracture, the curvature at the fracture site had to be identical in both nails.

- Regarding the entry point; a $2 \mathrm{~cm}$ skin incision at the required bone entry hole was made. Starting usually on the lateral side as it is easier.
- These holes were performed by a bone awl. The awl was directed diagonally at an angle of $30^{\circ}$ towards the far cortex to make the hole accommodating the direction of a progressing nail. In two patients the medial hole was performed by a 3.2 drill bit.

- The nail was held in a cannulated T- handle with the horizontal bar of the T-handle and the curved tip of the nail aligned in the same plane (this allowed identification of the curved tip as it passed along the medullary canal).

$\circ$ The nail was passed through the entry hole with the curved tip pointing distally. Once it goes in the medullary canal the nail was rotated to point to the direction in which it should be passed.

- The nail was driven up the canal by rotating the Thandle back and forth. With a mallet, the nail was gently tapped to cross the fracture site. The nail was advanced towards the metaphysis to anchor into the cancellous bone.

- The second nail was advanced either from a lateral entry or from a medial entry using the same rotating movements and light taps. However, it was never rotated on its own axis through a full $360^{\circ}$ to avoid wrapping itself around the first nail.

- Both nails were advanced and impacted at their final proximal points.

$\circ$ The nail entering the lateral cortex of the humerus ended just distal to greater tuberosity, while the second nail introduced either through the lateral entry or a medial entry ended at the same level but pointing towards the glenoid.

- Reduction of the fracture and position of the nails were confirmed with the image intensifier.

- The ends of both nails were cut, ensuring that one $\mathrm{cm}$ of each nail remains outside the entry hole lying against the supracondylar flare.

- Wound irrigation, closure in layers and sterile dressing were applied.

- In order to compress the fracture, manual pressure was applied at the elbow.

- Sixteen patients were immobilized in an arm sling; however four patients were put in U-shaped slab due to comminuted pattern of fractures.

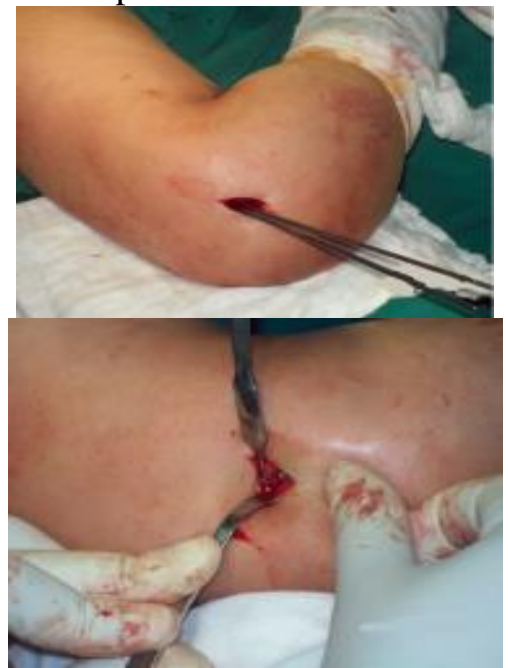

Figure (1): Nail cutting. 


\section{Postoperative care:}

- Every patient was examined for vascular and neurological status.

- Check X-rays were obtained to assess the reduction and the position of nails.

- Analgesics and anti-oedematous medications were prescribed.

- Patients were encouraged to flex the elbow and strengthen the elbow flexors from the first day postoperatively.

\section{Follow up:}

- Stitches were removed after two weeks.

- In sixteen patients, the arm sling was removed after three weeks and active shoulder exercises were allowed.

- In the four comminuted fractures the U-shaped slab was removed after three weeks and replaced by an arm brace for two further weeks, during which active shoulder exercises were allowed.

- Check X-rays (antero-posterior and lateral views) were obtained after two, six, and twelve weeks, then monthly till radiological union, then at the end of follow up.

- The mean follow up period was thirty-two weeks (range: from twenty-four to forty-eight weeks).

\section{Statistical analysis}

Recorded data were analyzed using the statistical package for social sciences, version 20.0 (SPSS Inc., Chicago, Illinois, USA). Quantitative data were expressed as mean \pm standard deviation (SD). Qualitative data were expressed as frequency and percentage.

\section{The following tests were done:}

- Chi-square $\left(\mathrm{x}^{2}\right)$ test of significance was used in order to compare proportions between two qualitative parameters.
- The confidence interval was set to $95 \%$ and the margin of error accepted was set to $5 \%$. The p-value was considered significant as the following:

- P-value $<0.05$ was considered significant.

- P-value $<0.001$ was considered as highly significant.

- P-value >0.05 was considered insignificant.

\section{RESULTS}

Age of patients (Table 1): The mean age was 33.85 \pm 6.24 years and the range was $14-65$ years old.

Gender (Table 2): Twelve patients were males (60\%) and eight patients were females (40\%).

Table (1): Age distribution among the studied group.

\begin{tabular}{||l|c|c||}
\hline Age & No. & \% \\
\hline$<30$ & 8 & 40.0 \\
$30-39$ & 7 & 35.0 \\
$40-49$ & 3 & 15.0 \\
$50+$ & 2 & 10.0 \\
\hline Range & \multicolumn{2}{|c|}{$14.00-65.00$} \\
\hline Mean \pm SD & \multicolumn{2}{|c|}{$33.85 \pm 6.24$} \\
\hline
\end{tabular}

Table (2): Gender distribution among the studied group

\begin{tabular}{||c|c|c||}
\hline Gender & No & $\%$ \\
Male & 12 & 60.0 \\
Female & 8 & 40.0 \\
\hline
\end{tabular}

The mean age of the patients that achieved an excellent outcome was $33.85 \pm 6.36$ years. The mean age of those patients who got a good outcome was $47.83 \pm 5.52$ years. The age of the patient who got a fair result was 33, whereas the age of the patient who got poor results was 31 . This difference of means was statistically significant, that the younger the patient the more rapid the fracture healing occurs (Table 3 ).

Table (3): Relationship between result and age:

\begin{tabular}{|c|c|c|c|c|c|c|c|c|}
\hline \multirow{3}{*}{ Age } & \multicolumn{8}{|c|}{ Result } \\
\hline & \multicolumn{2}{|c|}{ Excellent } & \multicolumn{2}{|c|}{ Good } & \multicolumn{2}{|l|}{ Fair } & \multicolumn{2}{|c|}{ Poor } \\
\hline & No. & $\%$ & No. & $\%$ & No. & $\%$ & No. & $\%$ \\
\hline$<30$ & 8 & 40.0 & 0 & $\overline{0.0}$ & 0 & 0.0 & 0 & $\overline{0.0}$ \\
\hline $30-39$ & 3 & 15.0 & 2 & 10.0 & 1 & 5.0 & 1 & 5.0 \\
\hline $40-49$ & 1 & 5.0 & 2 & 10.0 & 0 & 0.0 & 0 & 0.0 \\
\hline $50+$ & 0 & 0.0 & 2 & 10.0 & 0 & 0.0 & 0 & 0.0 \\
\hline МСp & \multicolumn{8}{|c|}{$0.014^{*}$} \\
\hline Range & \multicolumn{2}{|c|}{$14.00-65.00$} & \multicolumn{2}{|c|}{$35.00-65.00$} & \multicolumn{2}{|c|}{$33.00-33.00$} & \multicolumn{2}{|c|}{$31.00-31.00$} \\
\hline Mean \pm SD & \multicolumn{2}{|c|}{$33.85 \pm 6.36$} & \multicolumn{2}{|c|}{$47.83 \pm 5.52$} & \multicolumn{2}{|c|}{$33.00 \pm-$} & \multicolumn{2}{|c|}{$31.00 \pm-$} \\
\hline$\chi^{2}(p)$ & \multicolumn{8}{|c|}{$10.585^{*}(0.014)$} \\
\hline
\end{tabular}

MCp: $\mathrm{p}$ for Monte Carlo test

$\chi$ : Chi square for Kruskal Wallis test, *: Statistically significant at $\mathrm{p} \leq 0.05$

There was no statistically significant relation between patient's gender and the final score (Table 4). 
Table (4): Relation between net results and patient's gender:

\begin{tabular}{|c|c|c|c|c|c|c|c|c|}
\hline \multirow{3}{*}{ Gender } & \multicolumn{8}{|c|}{ Result } \\
\hline & \multicolumn{2}{|c|}{\begin{tabular}{|l} 
Excellent \\
\end{tabular}} & \multicolumn{2}{|c|}{ Good } & \multicolumn{2}{|l|}{ Fair } & \multicolumn{2}{|c|}{ Poor } \\
\hline & No. & $\%$ & No. & $\%$ & No. & $\%$ & No. & $\%$ \\
\hline Male & 7 & 35.0 & 3 & 15.0 & 1 & 5.0 & 1 & $\overline{5.0}$ \\
\hline Female & 5 & 25.0 & 3 & 15.0 & 0 & 0.0 & 0 & 0.0 \\
\hline MCp & \multicolumn{8}{|c|}{1.000} \\
\hline
\end{tabular}

MCp: $\mathrm{p}$ for Monte Carlo test

There was no statistically significant relation between side affection and the final score (Table 5).

Table (5): Relation between net results and side affected.

\begin{tabular}{|c|c|c|c|c|c|c|c|c|}
\hline \multirow{3}{*}{ Side } & \multicolumn{8}{|c|}{ Result } \\
\hline & \multicolumn{2}{|c|}{ Excellent } & \multicolumn{2}{|c|}{ Good } & \multicolumn{2}{|c|}{ Fair } & \multicolumn{2}{|c|}{ Poor } \\
\hline & No. & $\%$ & No. & $\%$ & No. & $\%$ & No. & $\%$ \\
\hline Dominant & 5 & 25.0 & 4 & 20.0 & 1 & 5.0 & 1 & 5.0 \\
\hline $\begin{array}{l}\text { Non } \\
\text { dominant }\end{array}$ & 7 & 35.0 & 2 & 10.0 & 0 & 0.0 & 0 & 0.0 \\
\hline MCp & \multicolumn{8}{|c|}{0.538} \\
\hline
\end{tabular}

MCp: $\mathrm{p}$ for Monte Carlo test

There was no statistically significant relation between the level of the fracture and the final score (6)

Table (6): Relationship between result and level of fracture.

\begin{tabular}{|c|c|c|c|c|c|c|c|c|}
\hline & \multicolumn{8}{|c|}{ Result } \\
\hline & \multicolumn{2}{|c|}{ Excellent } & \multicolumn{2}{|c|}{ Good } & \multicolumn{2}{|c|}{ Fair } & \multicolumn{2}{|c|}{ Poor } \\
\hline & No. & $\%$ & No. & $\%$ & No. & $\%$ & No. & $\%$ \\
\hline 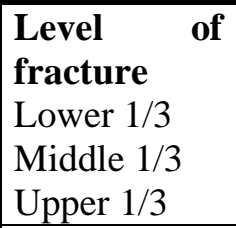 & $\begin{array}{l}2 \\
7 \\
3 \\
\end{array}$ & $\begin{array}{l}10.0 \\
35.0 \\
15.0\end{array}$ & $\begin{array}{l}1 \\
5 \\
0 \\
\end{array}$ & $\begin{array}{l}5.0 \\
25.0 \\
0.0\end{array}$ & $\begin{array}{l}0 \\
1 \\
0\end{array}$ & $\begin{array}{l}0.0 \\
5.0 \\
0.0\end{array}$ & $\begin{array}{l}0 \\
1 \\
0\end{array}$ & $\begin{array}{l}0.0 \\
5.0 \\
0.0\end{array}$ \\
\hline MCp & 0.887 & & & & & & & \\
\hline
\end{tabular}

MCp: $\mathrm{p}$ for Monte Carlo test

There was no statistically significant relation between the shape of the fracture and the final score (Table 7).

Table (7): Relationship between result and shape of fracture.

\begin{tabular}{||l|c|c|c|c|c|c|c|c|}
\hline \multirow{2}{*}{ Shape of fracture } & \multicolumn{7}{|c|}{ Result } \\
\cline { 2 - 11 } & Excellent & \multicolumn{2}{|c|}{ Good } & \multicolumn{2}{|c|}{ Fair } & \multicolumn{2}{c|}{ Poor } \\
\cline { 2 - 10 } & No. & $\%$ & No. & $\%$ & No. & $\%$ & No. & $\%$ \\
\hline Oblique & 3 & 15.0 & 2 & 10.0 & 0 & 0.0 & 0 & 0.0 \\
Transverse & 5 & 25.0 & 3 & 15.0 & 1 & 5.0 & 1 & 5.0 \\
Spiral & 1 & 5.0 & 0 & 0.0 & 0.0 & 0.0 & 0 & 0.0 \\
Minimally comminuted & 2 & 10.0 & 1 & 5.0 & 0 & 0.0 & 0 & 0.0 \\
Comminuted & 1 & 5.0 & 0 & 0.0 & 0 & 0.0 & 0 & 0.0 \\
\hline MCp & \multicolumn{10}{|c|}{0.811} \\
\hline
\end{tabular}

MCp: $\mathrm{p}$ for Monte Carlo test

There was no statistically significant relation between mechanism of trauma and the final score (Table 8): 
Table (8): Relation between results and mechanism of trauma.

\begin{tabular}{|c|c|c|c|c|c|c|c|c|}
\hline & \multicolumn{8}{|c|}{ Result } \\
\hline & \multicolumn{2}{|c|}{ Excellent } & \multicolumn{2}{|c|}{ Good } & \multicolumn{2}{|c|}{ Fair } & \multicolumn{2}{|c|}{ Poor } \\
\hline & No. & $\%$ & No. & $\%$ & No. & $\%$ & No. & $\%$ \\
\hline Trauma & & & & & & & & \\
\hline RTA & 6 & 30.0 & 3 & 15.0 & 1 & 5.0 & 0 & 0.0 \\
\hline FFH & 5 & 25.0 & 3 & 15.0 & 0 & 0.0 & 0 & 0.0 \\
\hline Assault & 1 & 5.0 & 0 & 0.0 & 0 & 0.0 & 1 & 5.0 \\
\hline МCp & \multicolumn{8}{|c|}{0.357} \\
\hline
\end{tabular}

MCp: $\mathrm{p}$ for Monte Carlo test

FFH: Falling from height

\section{Cases presentations:}

Patients (1)

A 35 year-old male, a driver, he had a spiral fracture of the lower third of his right humerus. Closed reduction and internal fixation using two retrograde flexible intramedullary titanium nails (diameter: $3.5 \mathrm{~mm}$ ) was performed through the lateral and medial humeral condyles, as the fracture was in the lower third of the humerus. Postoperatively, he was encouraged to gradually start active elbow and shoulder exercises in arm brace after three weeks. Nails were removed after six months due to pain at the insertion site, at that time; the fracture was united both clinically and radiologically. Follow up continued for two months after nails retrieval, and the outcome was graded as excellent (Fig. 2)

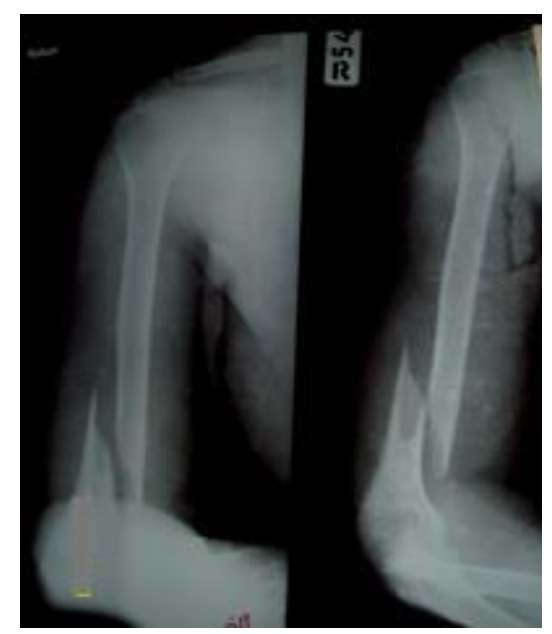

Figure (2a): Preoperative AP and lateral views.
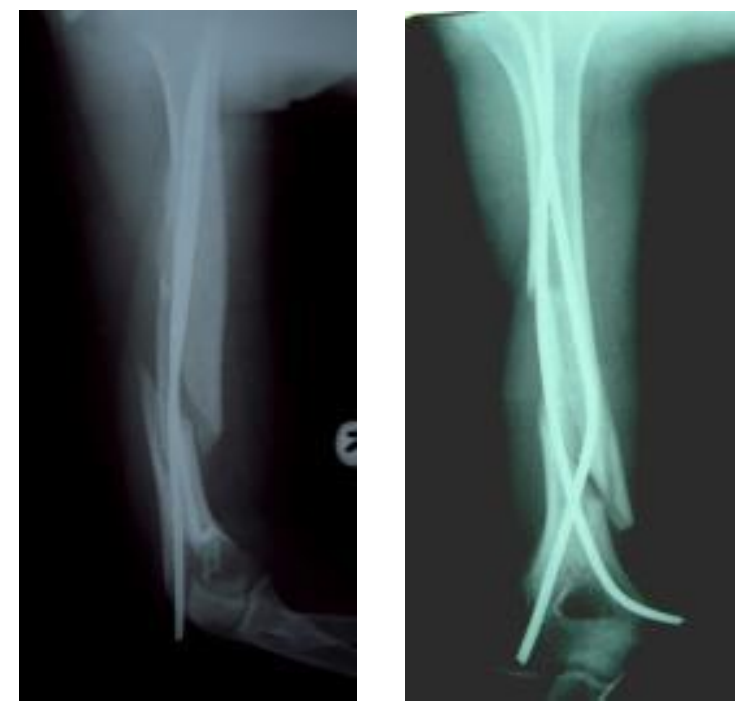

Figure (2b): Postoperative AP and lateral views. 
Evaluation of the Results of Management of Humeral Shaft Fractures...
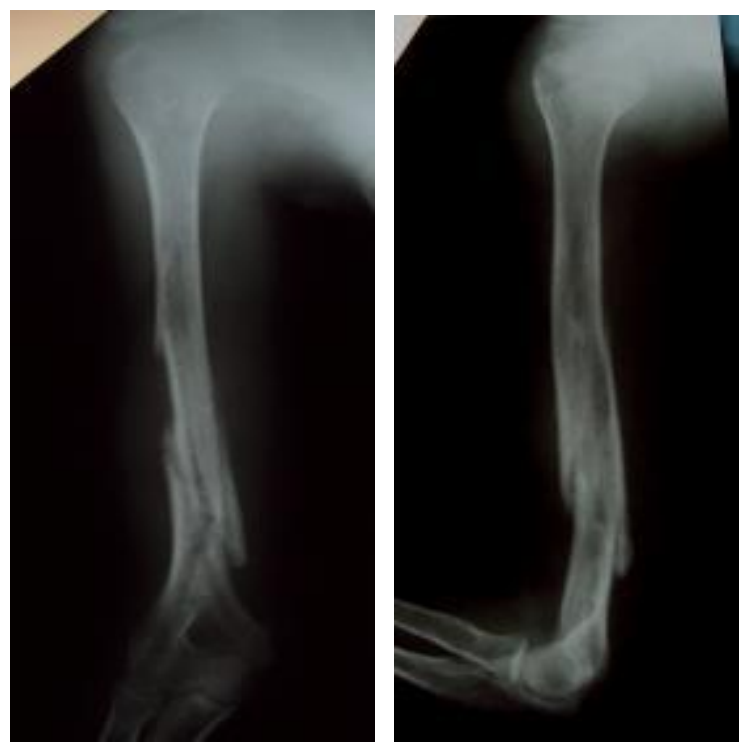

Figure (2c): AP and lateral views two months after removal of nails.
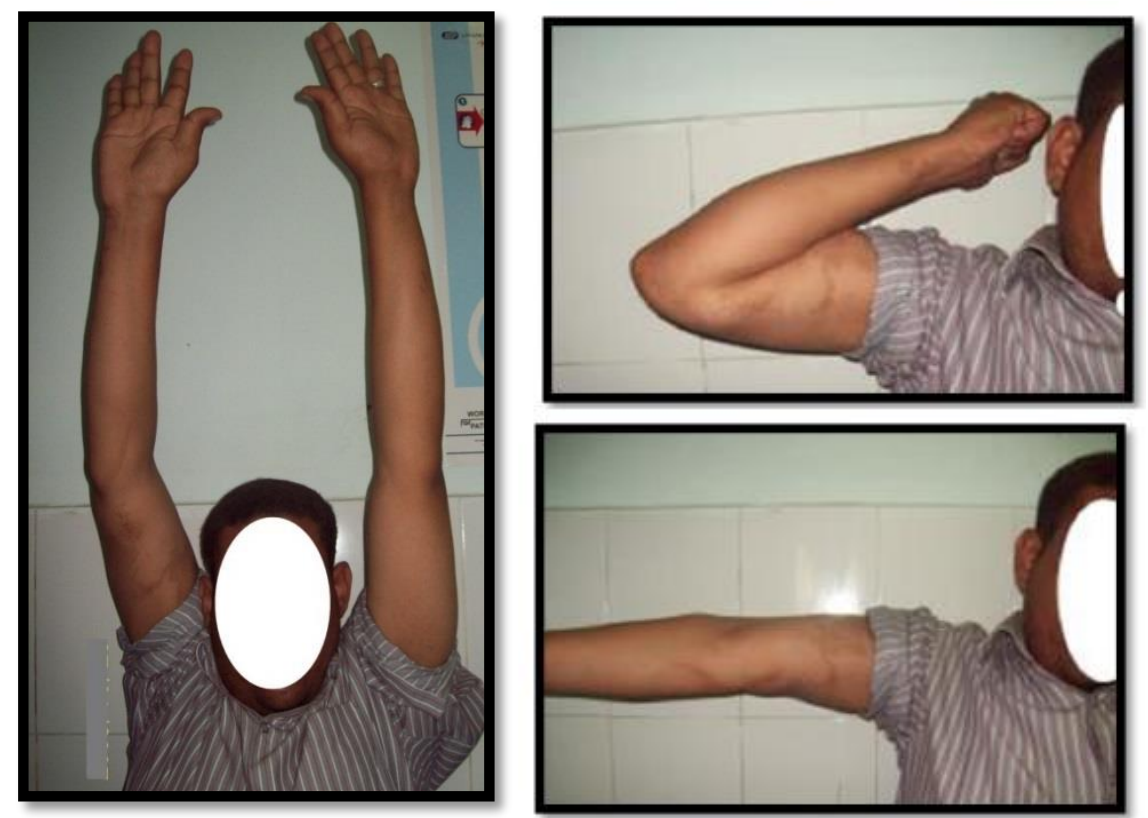

Figure (2d): Shoulder abduction.

Figure (2e): Elbow flexion and extension.

\section{Patient (2):}

A 31 year-old male, a manual worker, he had a fracture of the middle third of the right humerus, associated with ipsilateral fracture of the acromion. Closed reduction and internal fixation using two retrograde flexible intramedullary titanium nails (diameter: $3 \mathrm{~mm}$ ) was carried out through the lateral humeral condyle, as the fracture was in the middle third of the humerus. Nails were smaller than the ideal diameter as the humeral canal diameter was $11 \mathrm{~mm}$. The nails were not ideally fitted proximally. X-rays done after three and six months showed hypertrophic non-union. Open reduction and internal fixation with bone graft were done after seven months. Sixteen weeks later, patient's outcome did improve. According to the used scoring system the results before the second operation were graded as poor results (Fig. 3). 
Gad Abdel Baki et al.

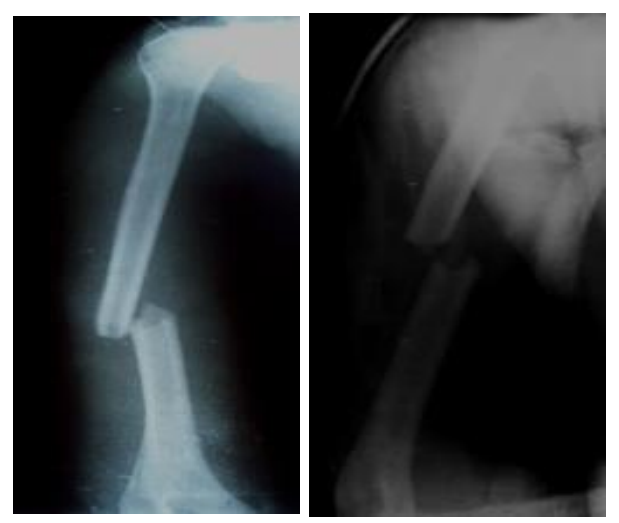

Figure (3a): Preoperative AP and lateral views.

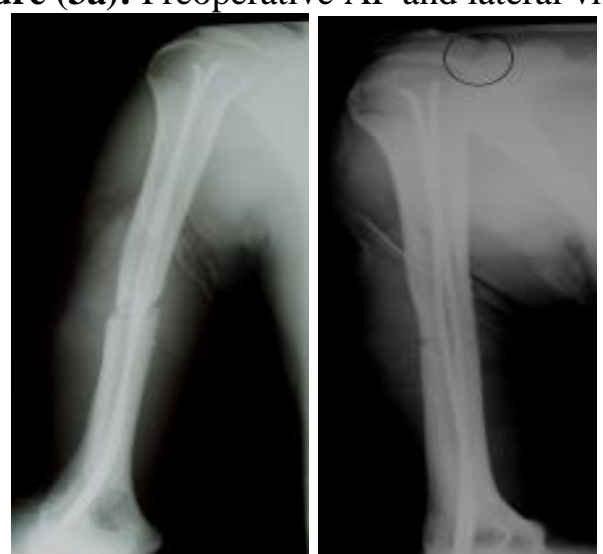

Figure (3b): Postoperative AP and lateral views.

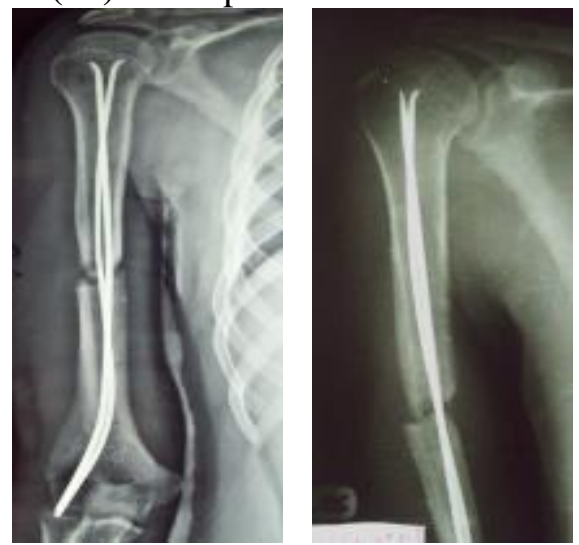

Figure (3c): AP and lateral views after six months.

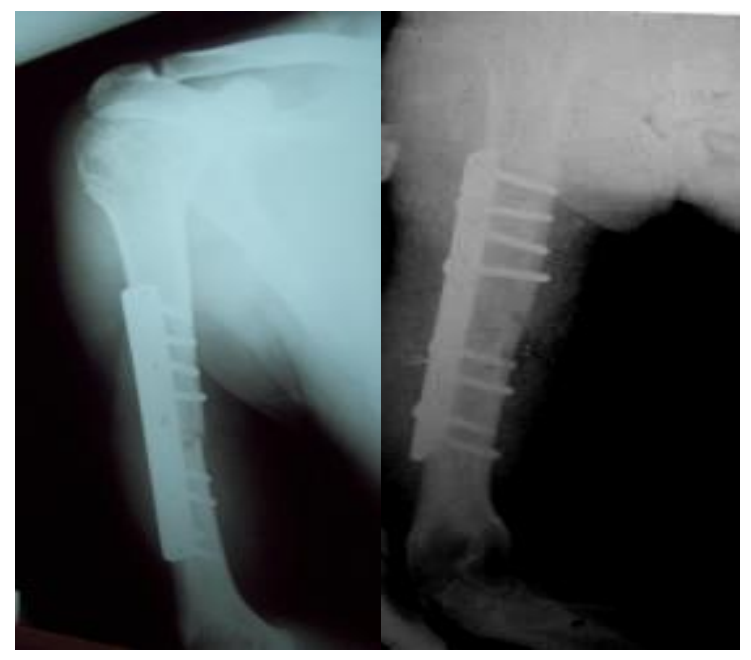

Figure (3d): AP and lateral views after open reduction and internal fixation and bone grafting. 


\section{DISCUSSION}

The humerus is the most mobile long bone of the upper limb. Humeral shaft fractures comprise about 3 to $5 \%$ of all body fractures ${ }^{(1)}$.

The aim of the present work was to assess the results of using the flexible intramedullary nails (Elastic stable intramedullary nailing; ESIN) in the management of humeral shaft fractures in different ages. ESIN functions as an internal splint, maintains the fracture hematoma and provides biological fixation. It is usually performed through a closed technique. Even when open reduction is required, a minimal approach is usually adequate to facilitate reduction, with minimal periosteal stripping. Furthermore, fixation fulfils the three points principle for each pin. Both elasticity and stress distribution of the titanium elastic nails facilitate callus formation ${ }^{(8,9)}$.

In this study, pre-bent elastic stable nails were used to treat humeral shaft fractures. This method of treatment was applied for 19 closed fractures and one open fracture treated at Alexandria Police Hospital and El-Zahra University Hospital.

These nails were introduced through the lateral humeral condyle alone in ten patients with upper and middle third fractures using a $\mathrm{C}$ and $\mathrm{S}$-shaped pre-bent elastic stable nails. While in middle to lower and lower third humeral shaft fracturs both medial and lateral condyles were used in ten patients using two C-shaped nails to avoid valgus angulation that may occured if a lateral entry only was utilized ${ }^{(10)}$.

According to Stewart and Hundley's ${ }^{(11)}$ scoring system, the results obtained after a mean follow up time of 32 weeks, were excellent in twelve patients $(60 \%)$, good in six patients $(30 \%)$, fair in one patient (5\%), and poor in another one patient (5\%). The results obtained were found comparable to the results of other studies that used different methods for humeral fixation $^{(4,7)}$.

The average age of these patients was 33.85 years which was less than the average age reported in most of the studies published on such injury, a fact that can be explained by increased number of high velocity injuries included in this study ${ }^{(7)}$.

In the present study the mean age of patients achieved excellent outcome was 33.85 years, whereas the mean age of patients achieved good outcome was 47.83 years. While for fair results the age was 33.0 years, and for poor results it was 31.0 years. The difference between excellent and good groups was statistically significant, that the younger the patient the more rapid the fracture healing occurs.

This was similar to that reported by Osman et al. (4). They found that the age of the patient had a great effect on the duration needed for fracture healing, with better results in younger patients. Osman et al. compared the different methods of fixation of humeral shaft fractures in 104 diaphyseal fractures of the adult humerus. 32 patients were treated non-operatively, 28 fractures were treated using plates and screws, 22 fractures were treated using multiple flexible intramedullary nails and 22 fractures were treated using an intramedullary antegrade Seidel nail ${ }^{(4)}$.

Similar observations were reported by Niall $\boldsymbol{e t}$ al. ${ }^{(12)}$ on 49 patients with humeral shaft fractures fixed with plate and screws.

However, these were different from what reported by Hall et $\boldsymbol{a l} .{ }^{(8)}$, who found no relation between the age and the fracture healing. They compared ender nails and conservative methods in fixation of acute humeral fractures, the study was done on 88 patients fixed with ender nails and 184 patients treated with a cast. ${ }^{(70)} \cdot \mathrm{In}$ this study, periosteal callus was usually visible radiologically with a mean of 6.1 weeks. This duration is longer than that reported by Hall et al. ${ }^{\left({ }^{(8)}\right.}$ using ender nails in treating humeral shaft fractures as the first periosteal callus appeared at an average of 19.9 days. Fracture geometry and its location are important determinants for selection of the most appropriate surgical technique. Transverse, short oblique and minimally comminuted fractures are suitable for ESIN (4).

In the present study; shape, level and type of the fracture had no significant impact on the final score.

Hall et $\boldsymbol{a l} .{ }^{(\boldsymbol{8})}$, observed that spiral and comminuted fractures gave better results than transverse fractures of the humeral shaft. Martinez et $\boldsymbol{a l} .{ }^{(13)}$, reported the same result with Marchetti nailing of closed fresh humeral fractures. They had a study on 143 patients with humeral shaft fractures fixed with retrograde nailing with Marchetti nail.

In the early postoperative days of the present study, the patients felt occasional crepitus of the fractured bone, which was not truly painful; but was disconcerting to the patients and prevented them from exercising the shoulder and elbow. Later on, as callus was forming, the range of motion improved steadily.

In the present series we obtained a full range of shoulder motion in 17 patients $(85 \%)$. Shoulder range of motion was partially limited in three patients. Two patients had $45^{\circ}$ of limited shoulder abduction and were associated with proximal migration of the nails through the greater tuberosity. After the nails were removed, the abduction range improved by $30^{\circ}$. One patient developed fracture non-union and had same limitations of shoulder motion. After 28 weeks the nails were removed, internal fixation and bone grafting were done. Sixteen weeks later, shoulder motion gradually improved achieving $100^{\circ}$ abduction, $30^{\circ}$ adduction, $90^{\circ}$ flexion, $30^{\circ}$ extension, $20^{\circ}$ external rotation, $30^{\circ}$ internal rotation.

In the present work, at the end of follow up, $75 \%$ of the patients had full elbow range of motion, $20 \%$ had elbow extension loss about $15^{\circ}$ after the nails had removed, and one patient $5 \%$, who developed nonunion, had elbow extension loss about $60^{\circ}$, but it improved gradually to $30^{\circ}$ after sixteen weeks of internal fixation by a plate and screws. 
Martinez et al ${ }^{(13)}$ reported an excellent elbow function in $39.1 \%$ of patients, good in $62 \%$ of patients, fair in $12.6 \%$ of patients, and poor in $4.9 \%$ of patients. The introduction of pre-bent elastic stable nails through the humeral condyles was difficult and time consuming in the first few patients, but later the gained experience made the operation easier and faster. The operating time decreased from 90 minutes in the first two patients to 30 minutes in the last few patients. The mean operative time for all patients who were fixed through both condyles, was 56.5 minutes and was 36 minutes for those who were fixed through the lateral humeral condoyle only. It was noticed that the middle and upper third fractures had the shortest operative time compared to fractures occurring at lower third. This was probably because of the wider medullary canal in the proximal third and due to fixation through the lateral and medial humeral condyles in lower third fractures ${ }^{(6,14)}$.

The mean operative time in this study was shorter than that reported by Hall $\boldsymbol{e t}$ al. ${ }^{(8)}$ using ender nails (76 minutes), and Niall et al. ${ }^{(12)}$ using plate and screws (115 minutes) and by Chao et al. 2005 ${ }^{(\mathbf{1 4})}$, using ender nails (52 minutes), antegrade interlocking nail (102 minutes) and plate and screws (110 minutes).

In this study, skin irritation due to prominent nail ends was a common problem encountered in eight (40\%) patients. They also had restriction of elbow extension. After nail retrieval elbow extension gradually improved and was fully restored in four patients, while the remaining four patients didn't and still had a $15^{\circ}$ elbow extension loss.

Osman et al. ${ }^{(4)}$ encountered this problem in $(56 \%)$ of their patients who were treated with multiple flexible nails via a supracondylar entry point. Radwan et al. $^{(15)}$ reported the same problem in (10\%) of the patients but it didn't interfere with elbow motion.

Non-operative treatment for fractures of the humerus in polytraumatized patients is difficult and reported to be associated with a high rate of non-union, difficult nursing, inadequately control fracture in supine position by any conservative method ${ }^{(15)}$. While, fixation simplifies nursing care, improves pulmonary toilet, enhances patient mobilization and rehabilitation, improves fracture alignment and functional results. Therefore, there is a growing tendency for early surgical stabilization ${ }^{(15)}$. The use of elastic stable nails in surgical stabilization of humeral diaphyseal fractures in multiply injured patient is a simple, easy semi rigid and quick technique with minimal morbidity. In the present study, we had four patients who had multiple injuries, three of them achieved good results and one patient got poor results. He had an associated fracture acromion, which might delay the early range of motion of the shoulder. Association of shoulder stiffness and delayed and nonunion after internal fixation of the humerus was also reported by Martinez et al. ${ }^{\left({ }^{(3)} \text {. In }\right.}$ this study, ten patients had their nails removed. Seven of them due to pain at insertion sites, one patient due to proximal migration, one patient due to both causes, and the last one due to non-union. It was performed as a day case procedure under general anesthesia, after an average period of six months (range from five to eight months postoperatively).

\section{CONCLUSIONS}

1. Flexible intramedullary nailing is a simple, easy semi rigid and quick technique for stabilization of humeral diaphyseal fractures in selected cases of humeral shaft fractures in different ages.

2. The procedure has low morbidity and expected to give good results with a short hospitalization.

3. Most of the associated complications can be avoided if the surgeon is strictly adhering to the basic principles and technical aspects.

\section{REFERENCES}

1. Garvanos C (2015): Humeral shaft fractures. In Court-Brown CM, Heckman JD, McQueen MM, Ricci WM, Tornetta PIII, eds. Rockwood and Green's Fractures in adults. 8th ed. Philadelphia: Wolters Kluwer Health, 2015:1287-336.

2. Sharma V, Awasthi B, Mehta SM et al. (2014): Evaluation of results of different treatment modalities in management of diaphyseal fractures of humerus. Indian Journal of Clinical Practice, 24(11):1068-74.

3. Clement ND (2015): Management of humeral shaft fractures; non-operative versus operative. Arch Trauma Res., 4(2):28-31.

4. Osman N, Touam C, Masmejean E et al. (1998): Results of non-operative and operative treatment of humeral shaft fractures. Ann Hand Surg., 17: 195- 206.

5. Gupta SK, Kumar MK, Reddy KR et al. (2014): Comparative study of management of humeral diaphyseal fractures by DCP plate and IMIL nail. Journal of Evolution of Medical and Dental Sciences, 17(7):1782-88.

6. Uhthoff HK, Poitras P, Backman DS (2006): Internal plate fixation of fractures: short history and recent developments. Journal of Orthopaedic Science, 11(2):118-26.

7. Bong MR, Koval KJ, Egol KA (2006): The history of intramedullary nailing. Bulletin of the NYU Hospital for Joint Diseases, 64(3and4):94-97.

8. Hall RF, Pankovich AM (1987): Ender nailing of acute fractures of the humerus J Bone Joint Surg., 69: 558-67.

9. Ajmal M, O'Sullivan M, McCabe J et al. (2001): Antegrade locked intramedullary nailing in humeral shaft fractures. Injury, 32: 692- 4 .

10. Knorr P, Joeris A, Lieber J et al. (2005): The use of ESIN in humerus fractures. Eur J Trauma, 31:12-8.

11. Stewart MJ, Hundley JM (1955): Fractures of the humerus; a comparative study in methods of treatment. J Bone Joint Surg Am., 37:681-692.

12. Niall DM, O'Mahony J, McElwain JP (2004): Plating of humeral shaft fractures has the pendulum swung back. Injury, 35: 580- 6 .

13. Martinez AA, Malillos M, Cuenca J et al. (2004): Marchetti nailing of closed fresh humeral shaft fractures. Chirugie de la main., 23:237-42.

14. Chao TC, Chung JC, Hsu CJ et al. (2005): Humeral shaft fractures treated by dynamic compression plates, Ender nails and interlocking nails. Int Orthop., 29: 88-91.

15. Radwan YA, El Feky A, Nassar Y (2008): Titanium Elastic Nail fixation of diaphyseal humeral fracture in multiply traumatized adolescent and young adults. Pan Arab J Orth Trauma, 12:67-74. 